\title{
Effect of Best Value Model Variables on Contractor Selection Decision
}

\author{
Ahmed H. Elyamany ${ }^{(1)}$ \\ ${ }^{(1)}$ Dep. of Construction Engineering \& Utilities, Zagazig University, Egypt
}

\begin{abstract}
Best-Value contracting is a mechanism that many agencies used to effectively implement projects with multiple objectives. It allows the government to acquire goods and services from the businesses that offer the Best-Value to the government, not simply the low-bid. The Low-bid contracting is false economy as the initial savings from price-based competition are erased by additional long-term costs. This paper discusses the implementation of the Best-Value concept in the procurement of construction projects. The main goal of the model implementation is studyingthe effect of changingBV model variables on the selection decision. Sensitivity analysis isconduct using scenarios of selection decisions. These scenarios are extremely important to the decision makers as it provide them with the reliability level and limitations of the model utilization. The paper provides both the decision makers and researchers with Sensitivity Charts that offer the guidelines for model implementation in real-world projects. Sensitivity Charts shows the effect of past performance data on the resulted Best-Value and the selected contractor as well.

Keywords: Best-Value;Sensitivity Analysis;Expected Performance;Past Performance
\end{abstract}

\section{Introduction}

Construction project owners are moving aggressively toward adopting a system that ensures only qualified contractors are competitively bidding on their construction projects. The current practice for many projects is to award them to the lowest responsible bidder. The decision maker role to select the best contractor within the short-list is only the lowest price. Therefore, the offer of the most qualified contractor might be rejected if increased the lowest bid by small percentage. Best-Value (BV) is the method that overcomes the sole source selection procedure problems by including factors other than the bid price in the selection decision. BestValue is defined as (Scott, Moenaar, Gransberg, \& Smith, 2006) "A procurement process where price and other key factors are considered in the evaluation and selection process to enhance the long-term performance and value of construction". This definition was disaggregated into four primary concepts; parameters, evaluation criteria, rating systems, and award algorithms.

A low-bid system encourages contractors to implement cost-cutting measures instead of quality enhancing measures. Therefore, it less likely that the contracts will be awarded to the best-performing contractors who will deliver the highest quality projects (NAVFAC, 1996). However, State and Federal Sectors, have moved aggressively towards the use of BV procurement, have attempted to measure its relative success, and are convinced that it achieves better results than low-bid. Contracts awarded on a Best-Value basis offer new opportunities for the selection of an overall high quality offer, rather than the low offer on service work. Best-Value selection enables the agency and stakeholders to collaboratively shape a particular project and provide contractual structure and incentive mechanisms that promote excellence. It establishes an effective basis for contract administration, and provides the framework for implementation monitoring and quality control. Best-Value criteria also provide clear benchmarks by which the agency, its critics, and other concerned stakeholders can judge project activities and outcomes (Carol Daly, 2006).

The federal agencies use Best-Value in a variety of ways (Sustainable Northwest, 2008). At times, the agencies develop comprehensive evaluation criteria based on diverse project goals, weigh price equal or greater to other factors combined, and evaluate non-price factors in detail. Too often, however, evaluation criteria are generic and evaluation processes focus on identifying the lowest cost, technically acceptable proposal. The agencies are inconsistent in their consideration of local community benefit as part of their evaluation.

\section{Procurement Reform Needs}

Construction projects suffer from serious losses during construction and along the life of the constructed facility. Most of these problems are caused by faults during construction that are related to the lack of the contractor experience. In Florida, for example, Construction industry is plagued with construction delays 
and cost overruns, poor workmanship, and unsafe work-sites leading to injuries and death (Marcos Feldman, 2006).

1. Construction Delays and Cost Overruns: Several key public construction projects throughout MiamiDade County have been delayed for years, including the North Terminal at Miami International Airport, almost \$1 billion over budget, years past due. The Performing Arts Center, reported to be at least \$102.1 million over budget, years behind schedule, and lacking adequate quality control. Construction-related change orders are the most frequent reason for construction delays, and these are typically caused by contractors.

2. Poor Workmanship: Miami-Dade's school district wasted more than $\$ 288$ million on delayed and substandard construction work, paid almost $\$ 8$ million fixing leaks, mold and other problems in new schools, and charged contractors $\$ 2.9$ million for the problems they created. The cost growth above the original price for many of these is estimated to be at least 30\%. In 2003, 77 recently built schools in Miami-Dade County had water leaks, and almost 40 had mold and mildew. County engineers had determined that in at least 14 cases poor construction was at fault.

3. Worker Health and Safety: Florida's construction industry is the most dangerous in the country for workers; we lead the nation in work-related deaths in the construction industry. In Miami-Dade County there have been calls for more regulation and inspections over large construction projects, where recently several workers have been critically injured or killed.

These Problems are Largely the Result of Low-Bid Contracting. Low-bid contracting is false economy as the initial savings from price-based competition are erased over the long-term because of inferior performance leading to additional costs. Low-bid contracting makes flawed assumptions, encourages cost-cutting and underperformance, and does nothing to screen out unscrupulous contractors (Marcos Feldman, 2006).

\section{Study Objectives}

The paper studies the implementation of the Best-Value model and the effect of parameters changes on the contractor selection using Sensitivity Analysis. Combinations of different selection alternatives are studied as project scenarios. These scenarios are extremely important to the decision makers as it provide them with the reliability level and limitations of the model utilization. The paper also provides the decision makers and researchers with Sensitivity Charts of the model parameters. Sensitivity Chart offers the guidelines for model implementation in real-world projects. The reliability of the contractor selection decision is relative to the amount of data available for the decision maker. The Best-Value model considers the construction project to have unique characteristics. The model provides the flexibility to select the appropriate parameters and their weights. The contractor score is assigned relative to the expected performance, whichobtained from the past performance.

\section{Best-Value Model}

A key concept in BV procurements is the focus on selecting the contractor with the offer "most advantageous to the government where price and other factors are considered." The factors other than price can vary, but they typically include technical and managerial merits, financial health, and past performance [(Gransberg and Senadheera, 1999), (Gransberg, Koch and Molenaar, 2006), (Gransberg and Ellicott, B. 1997)]. The BV procurement which is simple to implement, flexible in parameter selection and award algorithms, is the most effective approach in the context of a traditional bidding system (Abdelrahman, Zayed, Hietpas, \& Elyamany, 2008). In a broad sense, the BV strategy aims at using price and other key factors in the evaluation and selection process of bidders to enhance the long term performance of projects. The inclusion of key factors that match specific needs of a project guarantees that the selected contractor is the best to construct this project (Abdelrahman, Zayed, \& Elyamany, 2008). Most BV models include an evaluation process that is conducted based on subjective criteria. It is necessary for an agency implementing the BV to adopt a rational ranking system for contractor qualifications that is based on the agency's expected level of performance (Abdelrahman, Zayed, Hietpas, \& Elyamany, 2008). When used correctly, a BV selection rewards those who propose innovative concepts that enhance product quality or lower the price of quality. Owners should base BV selection criteria only on project elements that add measurable value to the project. Owners must think carefully of what is "valuable" in the product and not just "important" or "required" in the selection process. The algorithm used to combine parameter scores for the contractor is represented by the following equation(Abdelrahman, Zayed, \& Elyamany, 2008):

$$
B V_{j}=\sum_{i=1}^{n} P S_{i} \times W_{i}
$$

Where; $\mathrm{BV}_{\mathrm{j}}=$ Best-Value for contractor $\mathrm{j}, \mathrm{n}=$ number of parameters included in the $\mathrm{BV}$ equation, $\mathrm{PS}_{\mathrm{i}}=$ parameter i score, $\mathrm{W}_{\mathrm{i}}=$ weight of parameter $\mathrm{i}$. 
The above mentioned equation is added the weighted score for each parameter considered in the selection process. The BV model is flexible to include/exclude whatever parameter and evaluation criteria the owner considers important/non-important to score the contractor proposal. The development of the contractor score uses the idea of assigning the contractor score based on his expected performance. The contractor expected performance could be drawn from his past performance, assuming that the expected performance is equal to the mean of the past performance. Figure 1 shows how the parameter score is assigned to the contractor relative to the upper and lower limits for the parameter.

\section{Best-Value Parameters}

The Best-Value modelconsiders manyparameters including Bid Price, Rejected Claims, Lane Rental, and Quality (Abdelrahman et al. 2008). The BV parameters undergo a normalization process to provide the BV equation with a parameter score of 0 to 100. A parameter score of 100 is assigned to the full satisfaction level of a specific parameter to the owner. Two methods are available to calculate the Parameter score: (1) comparing the contractor to other contractors in the same project, (2) compares the contractor with the population of similar projects. Both methods use the Upper Reference Limit (URL) and the Lower Reference Limits (LRL) to assign the contractor the appropriate score. Figure 1 shows how parameter is scaled for a project where the bid offers ranges between $\$ \mathrm{X}-\mathrm{Y}$ Millions. Offers falling in between these two limits will receive a proportional scaled score. Comparing the contractor with others, bidding on the sameproject, uses the data of bidding contractors to set the URL and LRL. As shown in Figure 1, the URL is taken as the minimum bid (\$X) whilethe maximum bid $(\$ Y)$ is assigned a scaled score of 50 . The $\operatorname{LRL}(\$ Z)$ is then extrapolated using the 50 \& 100 scores.Comparing the contractor with the populationuses all loaded data to calculate the user-defined percentile for each parameter. The default is the 90th percentile for the URL and the 10th percentile for the LRL. This method only applies to random parameters (i.e. all parameters in the input files). Consider quality parameter, for example. If this option is selected and the 90th percentile is chosen as the URL, the software will find the point (\% Rejected) at which only $10 \%$ were better. To calculate this value, all projects matching the given work type and location from all contractors loaded into the software are used.

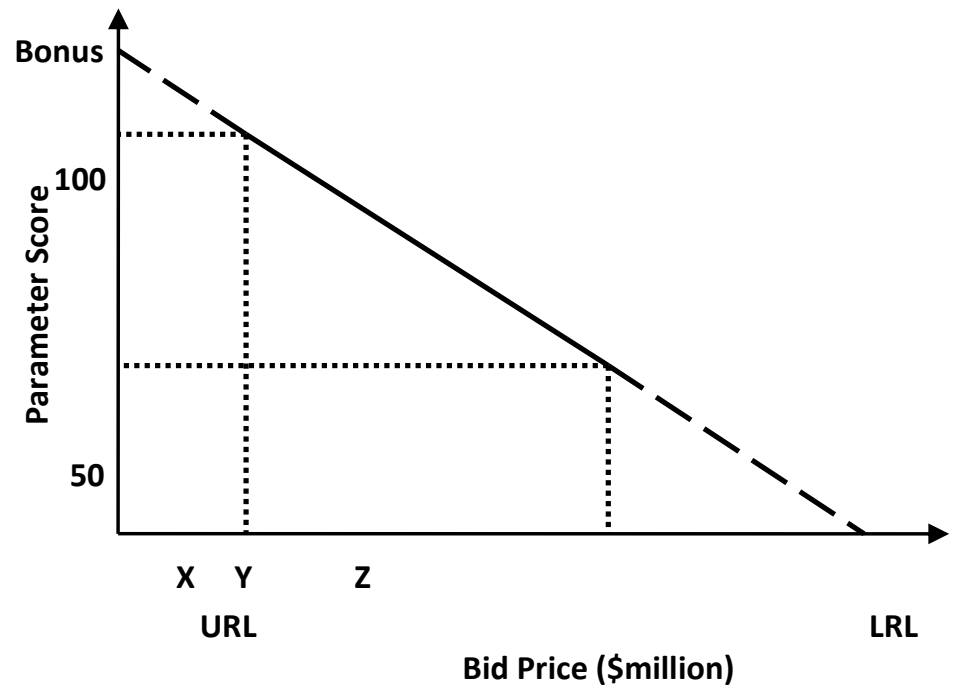

Figure 1 parameter score VS parameter value

\section{Parameter Weight}

A parameter weight (Wi) represents the decision maker's preference of the parameter importance indifferentiating among contractors. In other words, the parameter scheme represents the decision maker's priorities for a specific project. The summation of weights should be totaled to 100 .

\section{Sensitivity Analysis}

The significance of the sensitivity analysis is to set the guidelines of utilizing the BV model in awarding the project to the best contractor. The scenarios that are going to be considered in the analysis are;

- Choose the number of years of contractor past record that would be considered in the calculation of BestValue.

- Choose between including a single or multiple locations/districts to include in the calculations.

- Choose between including a single or multiple project types in the calculations. 
- Change the weights of parameters.

- Change the zero reference limit of each parameter.

Table 1shows a matrix of different scenarios that might occur during the selection process. The matrix includes 19 different scenarios as shown in Table 2. Each scenario will be implemented with the corresponding variables to calculate the resultant BV for each bidder. The resultant of this process will provide values that will be analyzed in the sensitivity analysis.

Table 1levels of BV model variables

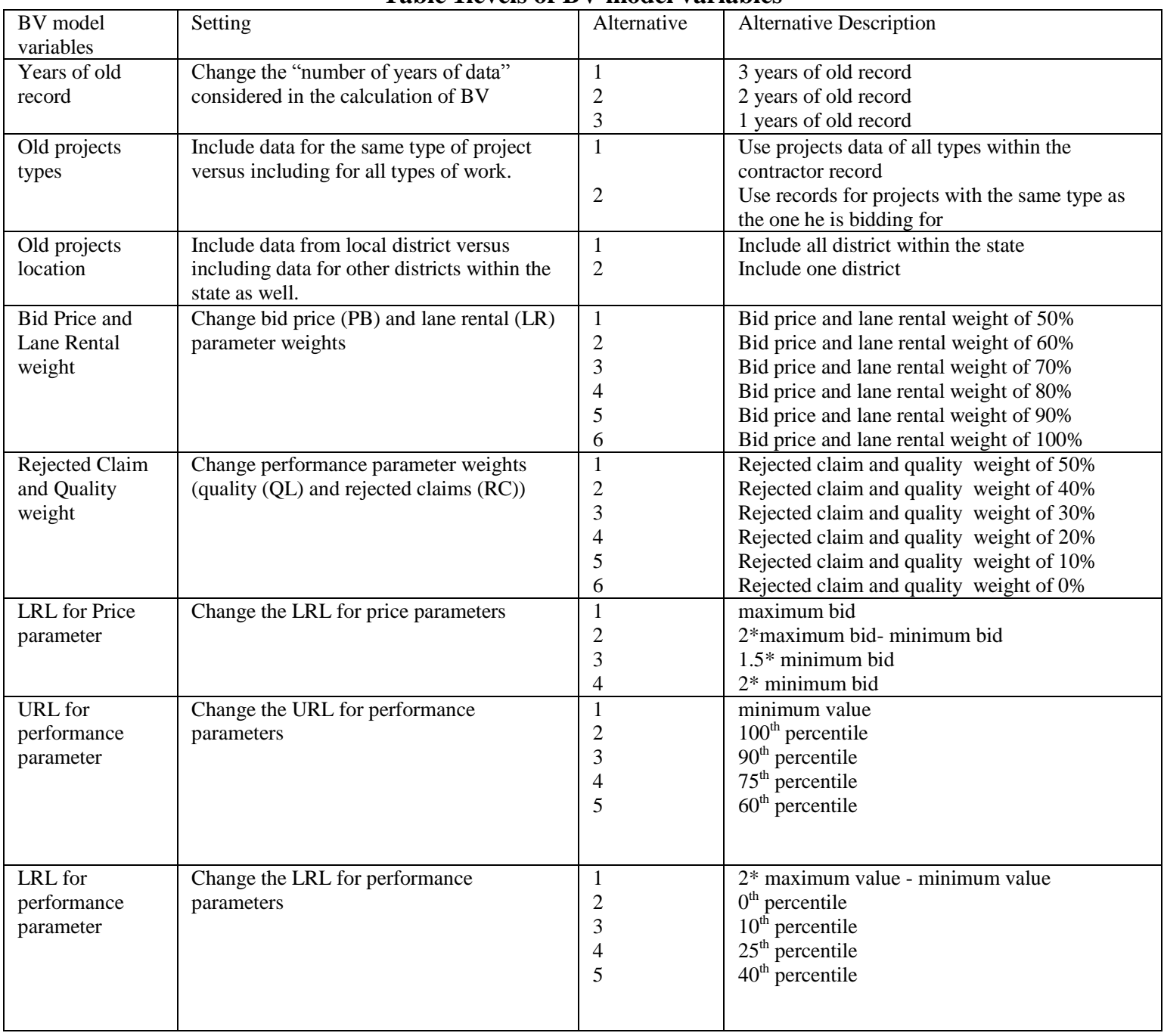

Table 2 Sensitivity Analysis Scenarios

\begin{tabular}{|c|c|c|c|c|c|c|c|c|c|c|}
\hline \multirow[t]{2}{*}{ Scenario } & \multirow[t]{2}{*}{ Year $^{1}$} & \multirow[t]{2}{*}{ Type $^{2}$} & \multirow[t]{2}{*}{ Location $^{3}$} & \multicolumn{4}{|c|}{ Weight } & \multirow[t]{2}{*}{ LRL for Price parameter $^{8}$} & \multirow{2}{*}{$\begin{array}{c}\text { URL for } \\
\text { performance } \\
\text { parameter }^{9}\end{array}$} & \multirow{2}{*}{$\begin{array}{c}\text { LRL for } \\
\text { performance } \\
\text { parameter }^{10}\end{array}$} \\
\hline & & & & $\mathrm{BP}^{4}$ & $\mathrm{LR}^{5}$ & $\mathrm{QL}^{6}$ & $\mathrm{RC}^{7}$ & & & \\
\hline 1 & 3 & $\mathrm{CP}$ & D1 & 50 & 20 & 15 & 15 & 2 Max Bid -Min Bid & min value & $2 \max -\min$ \\
\hline 2 & 2 & $\mathrm{CP}$ & D1 & 50 & 20 & 15 & 15 & $2 \max -\min$ & min value & $2 \max -\min$ \\
\hline 3 & 1 & $\mathrm{CP}$ & D1 & 50 & 20 & 15 & 15 & $2 \max -\min$ & min value & $2 \max -\min$ \\
\hline 4 & 3 & All & D1 & 50 & 20 & 15 & 15 & $2 \max -\min$ & min value & $2 \max -\min$ \\
\hline 5 & 3 & $\mathrm{CP}$ & All & 50 & 20 & 15 & 15 & $2 \max -\min$ & min value & $2 \max -\min$ \\
\hline 6 & 3 & All & All & 50 & 20 & 15 & 15 & $2 \max -\min$ & min value & $2 \max -\min$ \\
\hline 7 & 3 & $\mathrm{CP}$ & D1 & 30 & 20 & 25 & 25 & $2 \max -\min$ & min value & $2 \max -\min$ \\
\hline 8 & 3 & $\mathrm{CP}$ & D1 & 40 & 20 & 20 & 20 & $2 \max -\min$ & min value & $2 \max -\min$ \\
\hline 9 & 3 & $\mathrm{CP}$ & D1 & 60 & 20 & 10 & 10 & $2 \max -\min$ & min value & $2 \max -\min$ \\
\hline 10 & 3 & $\mathrm{CP}$ & D1 & 70 & 20 & 5 & 5 & $2 \max -\min$ & min value & $2 \max -\min$ \\
\hline 11 & 3 & $\mathrm{CP}$ & D1 & 80 & 20 & 0 & 0 & $2 \max -\min$ & - & - \\
\hline 12 & 3 & $\mathrm{CP}$ & D1 & 50 & 20 & 15 & 15 & Max Bid & min value & $2 \max -\min$ \\
\hline 13 & 3 & $\mathrm{CP}$ & D1 & 50 & 20 & 15 & 15 & $1.5^{*}$ Min Bid & min value & $2 \max -\min$ \\
\hline
\end{tabular}




\begin{tabular}{|l|l|l|l|l|l|l|l|l|l|l|}
\hline 14 & 3 & CP & D1 & 50 & 20 & 15 & 15 & $2 *$ Min Bid & min value & 2 max -min \\
\hline 15 & 3 & CP & D1 & 0 & 0 & 50 & 50 & - & min value & 2 max -min \\
\hline 16 & 3 & CP & D1 & 0 & 0 & 50 & 50 & - & $100^{\text {th }}$ percentile & $0^{\text {th }}$ percentile \\
\hline 17 & 3 & CP & D1 & 0 & 0 & 50 & 50 & - & $90^{\text {th }}$ percentile & $10^{\text {th }}$ percentile \\
\hline 18 & 3 & CP & D1 & 0 & 0 & 50 & 50 & - & $75^{\text {th }}$ percentile & $25^{\text {th }}$ percentile \\
\hline 19 & 3 & CP & D1 & 0 & 0 & 50 & 50 & - & $60^{\text {th }}$ percentile & $40^{\text {th }}$ percentile \\
\hline
\end{tabular}

${ }^{1}$ Years of history considered in the BV calculations

${ }^{2}$ Project's work type $(\mathrm{CP}=$ Concrete pavement included, $\mathrm{All}=$ all project types included $)$

3 Project's location (D1= District 1 included, All= all districts included)

${ }^{4}$ Parameters weight $(\mathrm{BP}=\mathrm{Bid}$ price $)$

5 Parameters weight $(\mathrm{LR}=$ Lane Rental)

6 Parameters weight (QL= Quality)

7 Parameters weight $(\mathrm{RC}=$ Rejected Claim)

8 LRL for Price parameter is upper limit of price parameters that get a score of zero.

${ }^{9}$ URL for performance parameter is lower limit of performance parameters that get a score of 100.

${ }^{10}$ LRLfor performance parameter is upper limit of performance parameters that get a score of zero.

\section{Case Study}

The sensitivity analysis discussed above is applied using the data for the construction project shown in Table 3. The data in this table represent the case study that demonstrates the implementation of the BV model. The decision makers receive offers from four contractors to construct the project. According to the characteristics of the offered job, the decision makers decided to base their selection decision on four parameters; bid price, lane rental, rejected claims and quality. The four parameters divided into two groups with two parameters each, Price group and Performance group. As shown in Table 3, all parameters are scored using the methodology discussed earlier, the offered values, and data records for Price and Performance parameters group, respectively. The resultant BV of these scenarios is shown in Table 4. The following sections will discuss the interpretations of these results.

Table 3Case Study Data

\begin{tabular}{|ll|c|c|c|c|}
\hline \multicolumn{7}{|c|}{ Contractor } & Bidder A & Bidder B & Bidder C & Bidder D \\
\hline \multicolumn{7}{|c|}{ Price Parameters } \\
\hline Bid Price & $(\$ \mathrm{M})$ & 1.25 & 1.3 & 1.4 & 1.35 \\
\hline Lane Rental & $(\$ \mathrm{M})$ & 0.2 & 0.21 & 0.19 & 0.18 \\
\hline \multicolumn{7}{|c|}{ Performance Parameters } \\
\hline Rejected Claims & $(\%)$ & 6.44 & 5 & 1 & 1.444 \\
\hline \multirow{2}{*}{ Quality } & IRI $(\%)$ & 2.9167 & 1.0163 & 2.3564 & 3.55 \\
\cline { 2 - 7 } & W/C $(\%)$ & 0.5484 & 3.5 & 1.096 & 3.52 \\
\hline
\end{tabular}

Table 4 Results of Sensitivity Analysis for the Case Study Scenarios

\begin{tabular}{|c|c|c|c|c|}
\hline \multirow{2}{*}{ Scenario } & \multicolumn{4}{|c|}{ Calculated BV } \\
\cline { 2 - 5 } & Bidder A & Bidder B & Bidder C & Bidder D \\
\hline 1 & $\mathbf{8 3 . 0 2}$ & 76.16 & 65.93 & 78.97 \\
\hline 2 & $\mathbf{8 5 . 8 3}$ & 81.67 & 56.67 & 75.83 \\
\hline 3 & $\mathbf{8 2 . 0 8}$ & 77.92 & 56.67 & 80.94 \\
\hline 4 & $\mathbf{8 5 . 8 3}$ & 81.57 & 68.82 & 78.58 \\
\hline 5 & $\mathbf{9 3 . 3 3}$ & 79.28 & 57.55 & 80.78 \\
\hline 6 & $\mathbf{8 5 . 4 9}$ & 80.85 & 68.41 & $\mathbf{8 2 . 7 3}$ \\
\hline 7 & 76.15 & 75.82 & 72.11 & $\mathbf{8 0 . 8 5}$ \\
\hline 8 & 79.59 & 75.99 & 69.02 & 77.09 \\
\hline 9 & $\mathbf{8 6 . 4 6}$ & 76.33 & 62.85 & 73.21 \\
\hline 10 & $\mathbf{8 9 . 9 0}$ & 76.50 & 59.76 & 62.30 \\
\hline 11 & $\mathbf{9 3 . 3 3}$ & 76.67 & 56.67 & $\mathbf{8 7 . 6 4}$ \\
\hline 12 & $\mathbf{7 6 . 3 6}$ & 57.82 & 37.60 & $\mathbf{9 1 . 6 4}$ \\
\hline 13 & 85.25 & 83.82 & 80.05 & $\mathbf{8 5 . 4 6}$ \\
\hline 14 & 87.47 & 89.16 & 87.16 & 87.02 \\
\hline 15 & 65.63 & 81.63 & 80.89 & 85.46 \\
\hline 16 & 88.48 & $\mathbf{9 8 . 3 3}$ & 80.56 & 80.09 \\
\hline 17 & $\mathbf{8 5 . 6 3}$ & 81.63 & 80.89 & $\mathbf{8 7 . 5 0}$ \\
\hline 18 & 40.63 & 50.00 & $\mathbf{8 0 . 8 9}$ & 80.89 \\
\hline 19 & 40.63 & 50.00 & & \\
\hline
\end{tabular}




\section{Effect of Changing the Number of Data Record on Best-Value}

Scenario \#1, 2 and 3 use the same inputs except the number of years of records considered in the analysis. Contractor past record are compared for 3, 2 and 1 year respectively. For these scenarios, the weight assigned to the performance parameters and price parameters are $30 \%$ and $70 \%$ respectively. The BV results for the three scenarios are slightly different due to the small relative weight of the performance parameters knowing that the four bidders' bids are relatively equal. It is expected that giving performance parameters a larger weight could cause a difference in the resultant Best-Value. Figure 2 shows the effect of changing the number of data record on BV and the bidders' ranking. It's obvious that there is an effect for the number of record years included in the calculations of BV. But because of the dominant weight of bid price over the weight of performance parameters, this effect is minimized. This effect could be noted in the change of rankings for bidder $\mathrm{B}$ and $\mathrm{D}$ however the winner is bidder $\mathrm{A}$ in all scenarios.

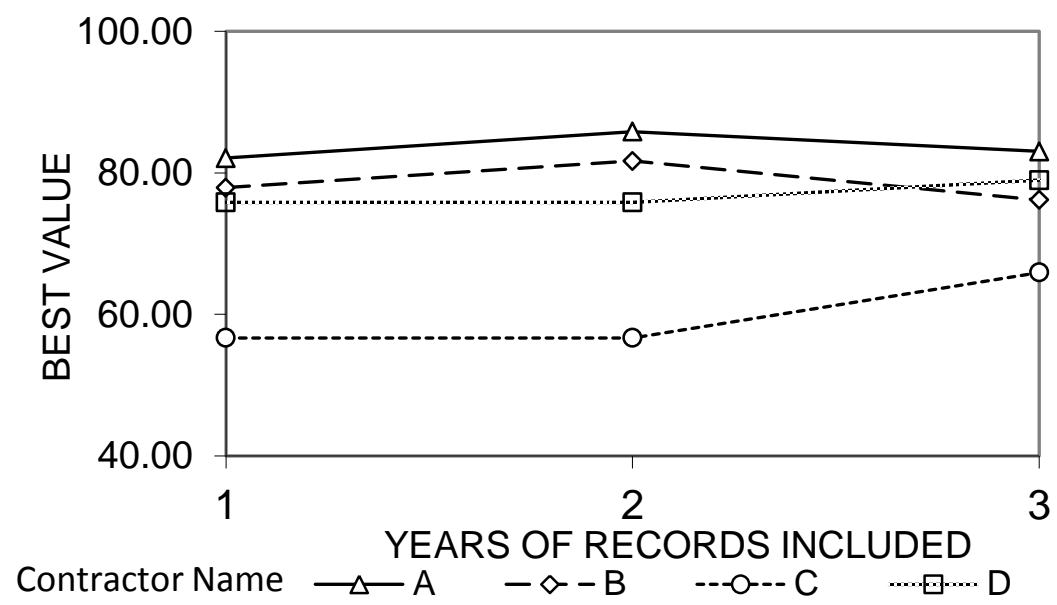

Figure 2 Effect of changing data record on $B V$

Effect of Changing the Included Work Types on Best-Value

Including data records for all project types within the analysis is represented in scenario \#4. The result of scenario \#4, where contractor past record of all work types is considered in the calculation, is compared to scenario \#1, where the past record only for concrete pavement is considered. The BV resulted from both scenarios are shown in Figure 3. This Figure does not show a significant change between the two scenarios. The reason behind this similarity is due to the small weights assigned to the performance parameters that make the total effect of changing the work type included in the calculation very insignificant.

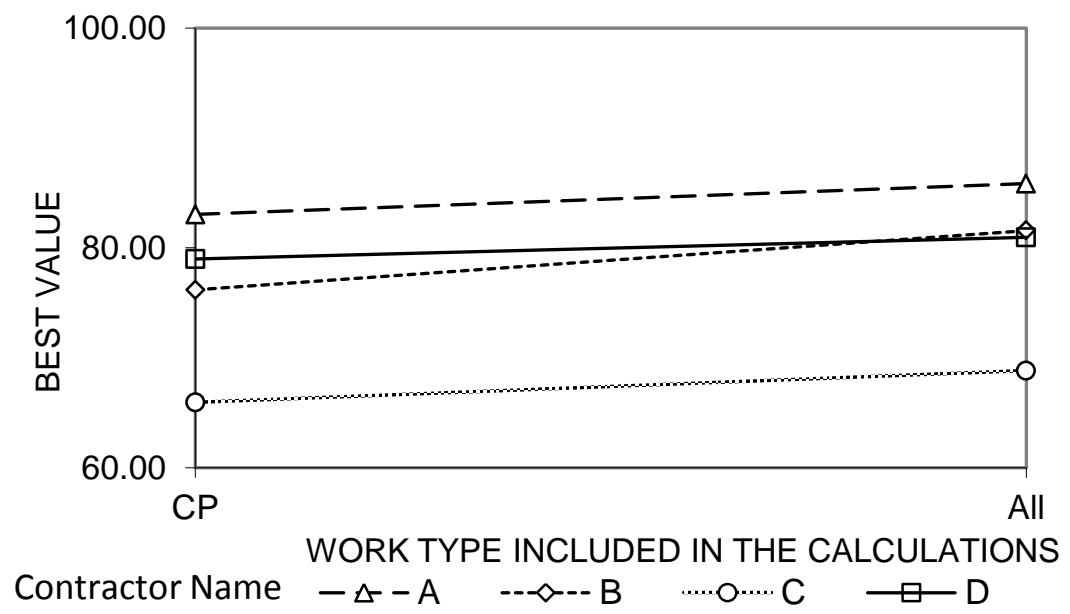

Figure 3 Effect of changing the included work types on BV

\section{Effect of Changing the Included Districts on BV}

Including contractor past records for all project locations within the analysis is represented in scenario \#5. The result of scenario \#5, where contractor past record for all project locations is considered in the calculation, is compared to scenario \#1, where only the past record of projects constructed in district 1 is considered. Bidders' rankings for both scenarios are the same that bidder A is the winner. The difference between the two scenarios is noticed when looking at Figure 4. BV of scenario \#5 is wide spread compared to 
scenario \#1. Bidder A gains more score when adding past record of his work in other districts to the calculation, while bidder $\mathrm{C}$ losses score by adding past record of his work in other districts. Both bidders B and D don't affected by adding past records of work in other districts. This result clearly shows the effect of considering past record for work done in other districts on the resulted BV.

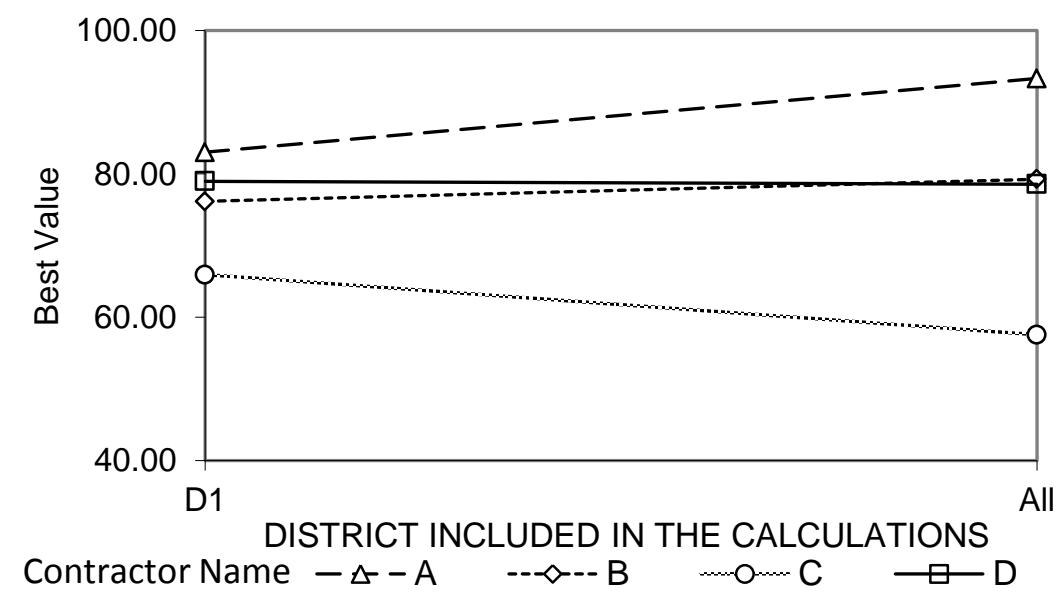

Figure 4 Effect of changing the included districts on $\mathrm{BV}$

\section{Effect of Changing Bid Price/Performance parameters Weight Ratio on Best-Value}

Scenarios 7,8,1,9,10, and 11 represent the difference occurs in BV, as a result to the change of bid price/performance parameters ratio of 50/50,60/40, 70/30, 80/20, 90/10, and 100/0 respectively. Figure 5 shows $\mathrm{BV}$ for different bid price/performance parameters ratio. As seen in the figure bidder ranking changed dramatically as the ratio changed. The threshold of this graph is 70/30 where all the bidders get closer values of $\mathrm{BV}$. This threshold could be different from project to another. The values of BV on the right side of the graph spread over a wider range. It could be noted also from the graph that bidders' rankings have changed with the change of bid price/performance parameters ratio. A better selection of bidder occurs when there is a significant difference between bidders BV, what makes the selection more reliable. Based on this rule, ratios 80/20, 90/10, and 100/0 give a reliable selection. In which scenario, the price parameters for all the bidders are too close.

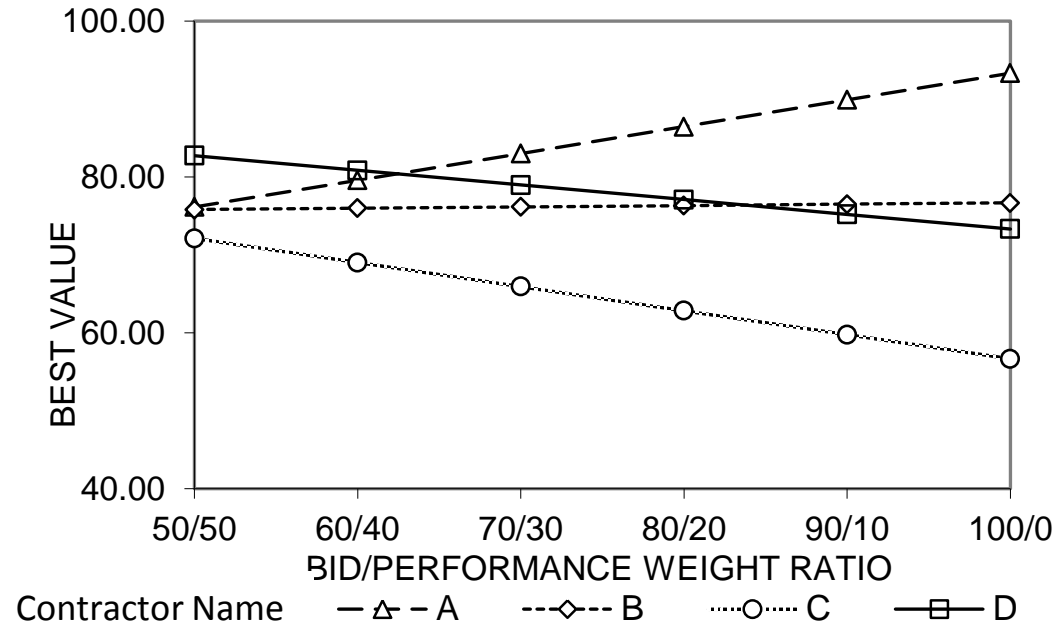

Figure 5 Effect of changing bid price/performance parameters weight ratio on $\mathrm{BV}$

\section{Effect of changing the Lower Reference Limit for Bid Price on Best-Value}

The Lower Reference Limit (LRL) for bid price is the limit where the bid price score is equal to 0 . LRL for bid price is calculated for (max. bid), (2*max. bid- min. bid), $(1.5 * \mathrm{~min}$. bid), and $(2 * \mathrm{~min}$. bid) in scenarios 12, 1, 13, and 14 respectively. The results of these scenarios are shown in Figure 6 below. It could be noted from the figure that the difference between the BV score is maximum when the LRL for bid price equals maximum bid, while this difference is minimum when LRL for bid price equals $(2 *$ min. bid). The reason for the minimum difference between the bidderBV at the LRL of $(2 * \mathrm{~min}$. bid) refers to the wide difference between the LRL and the bid prices of all other bidders. This distance makes the individual differences between contractors 
minimized. The better contractor selection scenario would be with a LRL equals maximum bid where there is a significant difference between bidders BV.

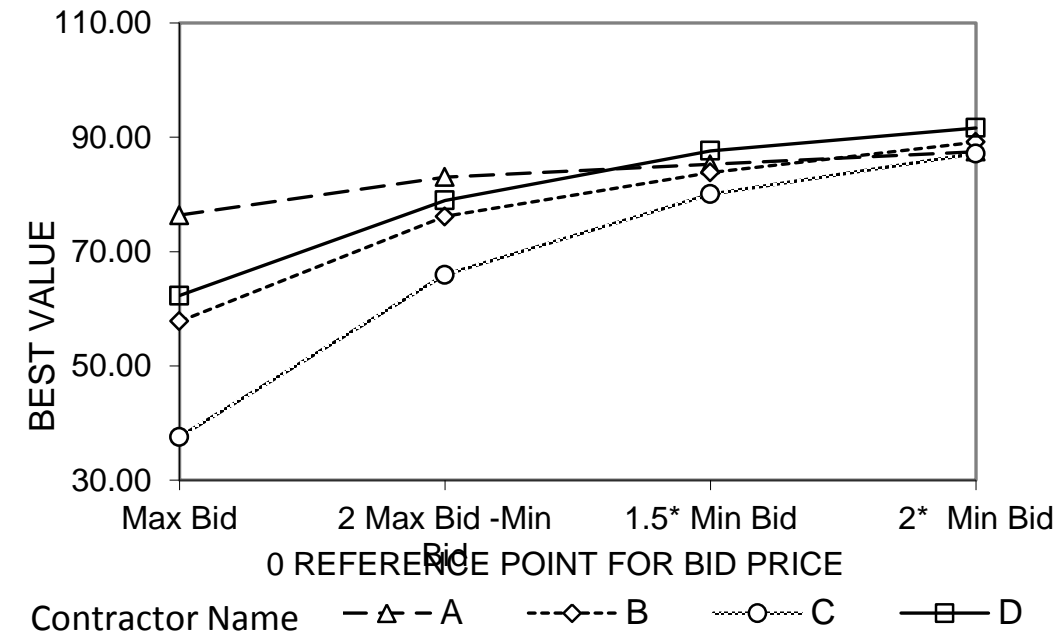

Figure 6 Effect of changing LRL for bid price on BV

\section{Effect of changing the LRL for Performance Parameters on Best-Value}

One way to calculate the bidder score of the performance parameters is to calculate it relative to the performance parameters for only the contractors who are bidding in the same project. The other way is to give this score based on a certain percentile of the whole population of contractors exist in the owner data base. Zero reference limits of performance parameters was assigned to the $100^{\text {th }}, 90^{\text {th }}, 75^{\text {th }}$, and $60^{\text {th }}$ percentile of contractor population for scenarios 16, 17, 18, and 19 respectively. As might be noticed from Figure 7, there are minor differences between theBV calculated for different contractors in scenariothe $100^{\text {th }}$ percentile population is used as the LRLs for performance parameters. According to the figure, a better contractor selection occurs when using the $60^{\text {th }}$ percentile of the population as LRL for performance parameters.

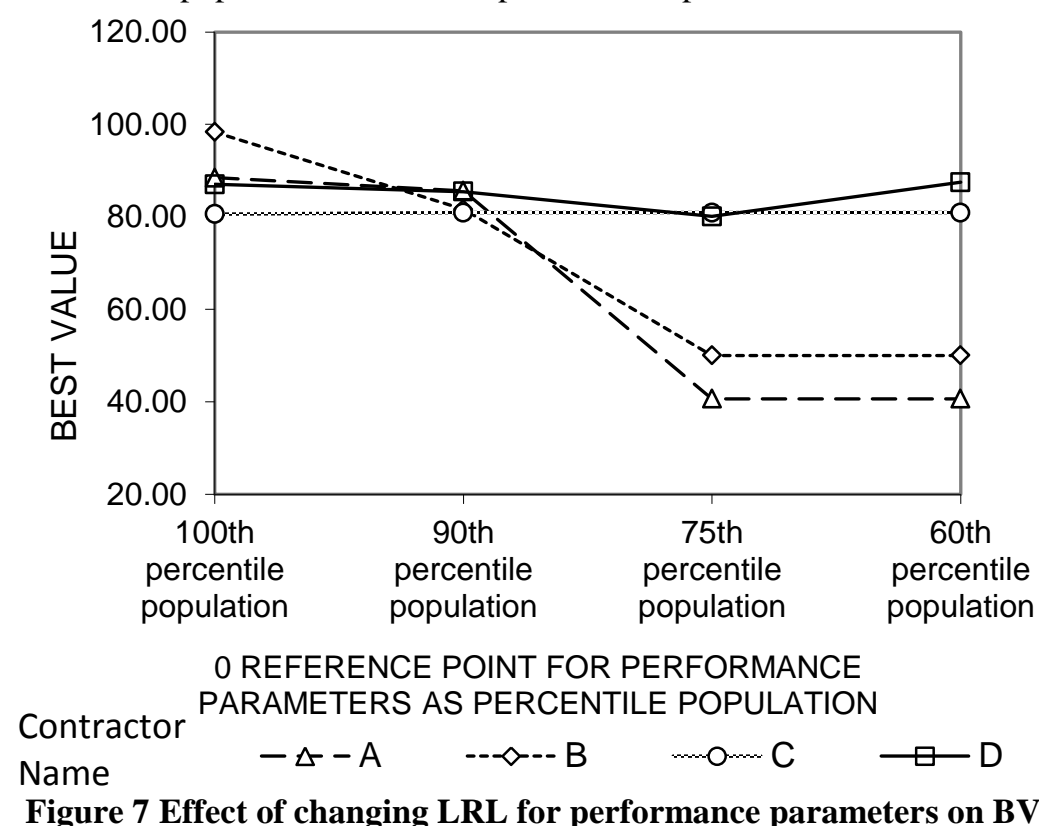

\section{Conclusion}

Best-Value contracting strategy aims at using price and other key factors in the evaluation and selection process to enhance the long term performance of projects. The inclusion of key factors that match the very specific needs of a specific project guarantees that the selected contractor is the best to construct the facility. The paper studied the effect of changing the variables of Best Value Model.The results of sensitivity analysis clearly show that a better selection would be more reliable and significant if the following condition occurs:

- More data records are used for the contractors such as data record for work done in other districts. 
- The implementation of the BVconcept would start with a higher weight assigned to bid price, between 80$90 \%$ of the total weight, at which the selection will depend on the lowest bidder and considering other performance parameters. The opposite scenariowould happen when the bid price weights between 20-30\% of the total weight leaving $70-80 \%$ of the total weight for the performance parameters. With this being the scenario, the selection will be based on the bidder with better performance.

- $\quad$ LRL for bid price set to the value of the maximumbid.

- LRL for performance parameters is equal to a specific percentile, i.e. $60^{\text {th }}$ percentile, is arbitrary and depends on the availability of records to support the selected value.

In broad sense, implementing BV on different project scenarios was successful in addressing the individual differences between projects. For a better contractor selection using BV, it is recommended first to havea solid contractor record database. Having a long history for the contractorwillselect the contractor with the minimum possible subjectivity and increase reliability of the selected contractor.

\section{References}

[1]. Abdelrahman, M., Zayed, T., \& Elyamany, A. (2008). Best-Value Model Based on Project Specific Characteristics. Journal of Construction Engineering and Management, 134 (3).

[2]. Abdelrahman, M., Zayed, T., Hietpas, J., \& Elyamany, A. (2008). Rational Best-Value Model Based on Expected Performance. TRB Annual Conference. Washington, D.C.

[3]. Carol Daly (2006) .Best Value and Stewardship Contracting Guidebook: Meeting Ecological and Community Objectives. Sustainable Northwest, Portland, OR.

[4]. Gransberg, D., \& Ellicott, M. (1997). Best-Value Contracting Criteria. Journal of Cost Engineering , 39 (6), 31 -34.

[5]. Gransberg, D., \&Senadheera, S. (1999). Design-Build Contract Award Methods for Transportation Projects. Journal of Transportation Engineering, 125 (6), 565-567.

[6]. Gransberg, D., Koch, J., \& Molenaar, K. (2006). Preparing for Design-Build Projects: A Primer for Owners, Engineers, and Contractors. VA: ASCE Press.

[7]. Marcos Feldman, 2006 "Best Value in Publicly Funded Projects: Contractor Selection in Two County GOB Projects.” Research Report, Research Institute on Social and Economic Policy, Florida International University, Miami, FL.

[8]. NAVFAC, N. F. (1996). Instructions for Developing Request or Proposals for Source Selection Design/Build Projects. Specification Instruction 00011. Pensacola, FL: Rep. code 076 (RAM/SHP).

[9]. Scott, S., Moenaar, K., Gransberg, D., \& Smith, N. (2006). Best-Value Procurement Methods for Highway Construction Projects. Washington, D.C.: transportation Research Board, National Research Council, Project No. 10-61.

[10]. Sustainable Northwest, Best Value Contracting Issue Paper, http://www.sustainablenorthwest.org/quick-links/resources/rvccissue-papers/Best\%20Value\%202007.pdf, last accessed Oct.2, 2008 